\title{
ВЛИЯНИЕ НОВЫХ ПРОИЗВОДНЫХ ГЕТЕРОЦИКЛИЧЕСКИХ СОЕДИНЕНИЙ НА ФИЗИЧЕСКУЮ РАБОТОСПОСОБНОСТЬ В ЭКСТРЕМАЛЬНЫХ ТЕМПЕРАТУРНЫХ УСЛОВИЯХ
}

\author{
(C) Петухова Н.Ф. ${ }^{1}$, Трошина М.В. ${ }^{1}$, Цублова Е.Г. ${ }^{1}$, Скачилова С.Я. ${ }^{2}$, Яснецов В.В. ${ }^{2}$ \\ ${ }^{1}$ Управление научно-образовательными инновациями \\ Брянского государственного инженерно-технологического университета, Брянск; \\ ${ }^{2}$ Всероссийский научный центр по безопасности биологически активных веществ, Старая Купавна \\ E-mail: etsublova@yandex.ru
}

В проведенных экспериментах на мышах установлено, что из испытанных 4 новых производных гетероциклических соединений два вещества - ЛХТ-4-97 и ЛХТ-1-13 - способны повышать физическую работоспособность животных по тесту плавания в бассейне в условиях как гипер-, так и гипотермии. В условиях иммерсионной гипертермии ЛХТ-4-97 в дозировке 10 мг/кг и ЛХТ-1-13 в дозировке 1 мг/кг увеличивают продолжительность плавания мышей на $25 \%$ и $23 \%$ соответственно, а в условиях иммерсионного охлаждения - на $25 \%$ и $16 \%$ соответственно. При этом по выраженности актопротекторного действия данные препараты не уступают используемому препарату сравнения ладастену, проявляющему свою активность в дозировке 50 и 100 мг/кг.

Ключевые слова: новые производные гетероциклических соединений, гипертермия, гипотермия, физическая работоспособность, актопротекторное действие.

\section{INFLUENCE OF NEW OF HETEROCYCLIC DERIVATIVES ON PHYSICAL EFFICIENCY IN EXTREME TEMPERATURE CONDITIONS}

Petukhova N.F. ${ }^{1}$, Troshina M.V. ${ }^{1}$, Tsublova E.G. ${ }^{l}$, Skachilova S. Ya. ${ }^{2}$, Yasnetsov V.V. ${ }^{2}$

${ }^{1}$ Management of Scientific and Educational Innovations of Bryansk State Engineering-Technological University, Bryansk; ${ }^{2}$ All-Russian Scientific Center of Biologically Active Substance Safety, Staraya Kupavna

The experiments on mice revealed that 2 of 4 new heteroaromatic derivatives and organic acid tested - LHT-4-97 and LHT-1-13 - were capable to improve the physical efficiency of animals in swimming test in a pool under conditions of hyperand hypothermia. LHT-4-97 in a dosage of $10 \mathrm{mg} / \mathrm{kg}$ and LHT-1-13 in a dosage of $1 \mathrm{mg} / \mathrm{kg}$ increased the duration of swimming by $25 \%$ and $23 \%$, respectively under conditions of immersion hyperthermia, and under conditions of immersion cooling $-25 \%$ and $16 \%$, respectively. At the same time they do not yeald in actoprotective action to the compared drugLadasten, which manifests its activity in dosage of 50 and $100 \mathrm{mg} / \mathrm{kg}$.

Keywords: new derivatives of heterocyclic compounds, hyperthermia, hypothermia, physical efficiency, actoprotective action.

Жизнь современного человека сопряжена с воздействием разнообразных неблагоприятных факторов окружающей среды. Несмотря на относительную независимость жизнедеятельности человека от действия метеофакторов, они остаются наиболее значимыми в плане поддержания работоспособности организма на должном уровне $[1,9]$.

Среди метеоусловий особое место занимает температура окружающей среды. Комфортная температура окружающей среды является обязательным условием сохранения высокой производительности человека на различных производствах. Кроме того, сами по себе высокие и низкие температуры могут также выступать фактором, ухудшающим здоровье и жизнедеятельность человека [2]. Поэтому вопрос поддержания физической работоспособности человека в неблагоприятных температурных условиях не теряет своей актуальности.
Из множества вариантов коррекции деятельности организма в условиях острого воздействия гипо- и гипертермии ведущая роль принадлежит лекарственным средствам. С целью повышения выживаемости и сохранения физической работоспособности на высоком уровне в условиях гипотермии в разные годы использовали психотропные средства (бромантан, фенамин и др.), препараты метаболического типа действия (яктон); в условиях гипертермии барбитураты, бензодиазепиновые анксиолитики, антигипоксанты (амтизол, гутимин), антиоксиданты (альфа-токоферола ацетат и др.), актопротекторы (метапрот) и др. [3, 10]. Значительная часть перечисленных лекарственных средств является по химической структуре гетероциклическими соединениями [8], что дало основание исследовать влияние новых производных гетероциклических соединений на физическую работоспособность животных в условиях острой гипер- и гипотермии. 


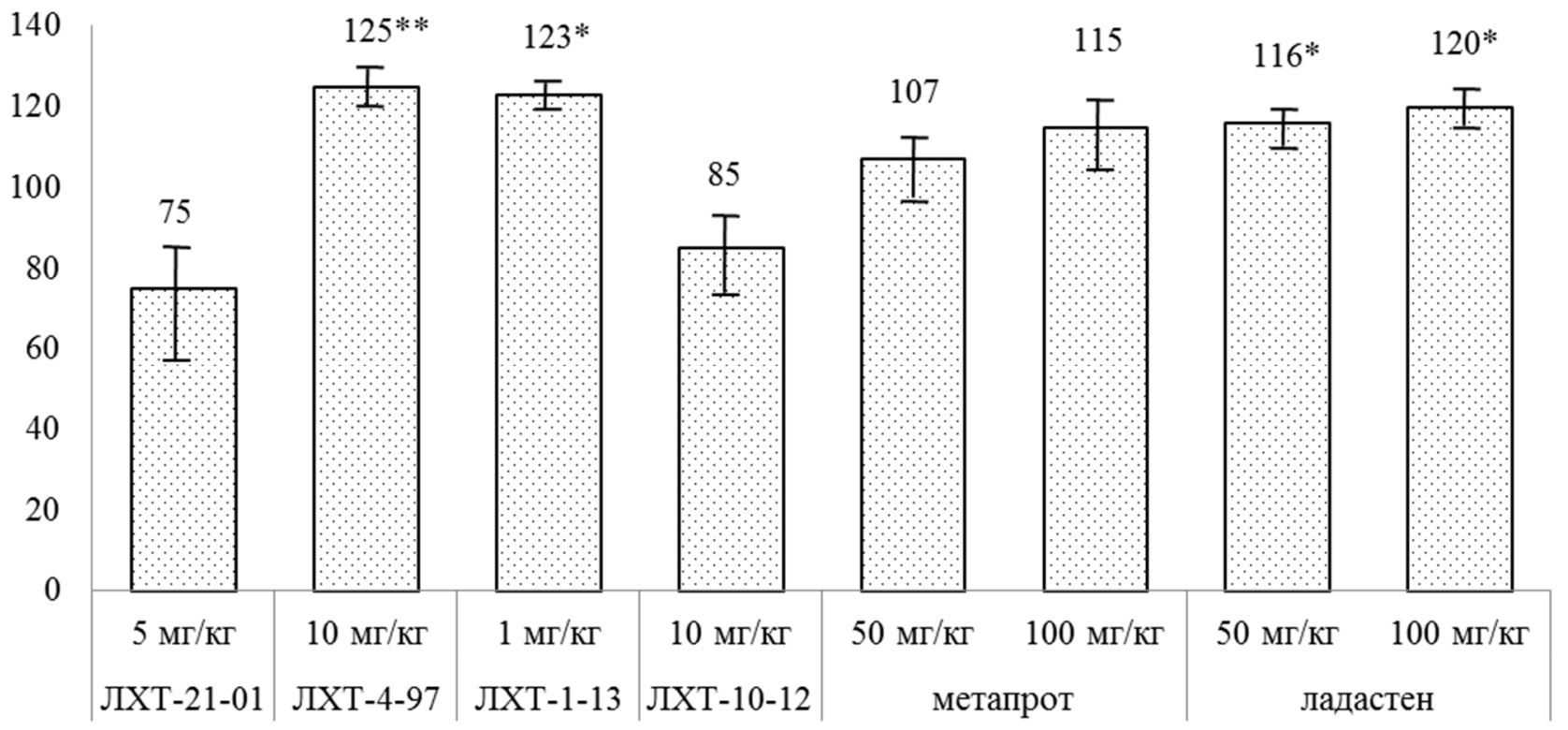

Рис. 1. Влияние исследованных соединений и препаратов сравнения на продолжительность плавания мышей в условиях иммерсионной гипертермии (в \% к контролю), $\mathrm{n}=8$.

Примечание: здесь и на рис. 2 различия статистически значимы по сравнению с контролем: * - p<0,05, ** - p<0,01 (критерий Стьюдента).

\section{МАТЕРИАЛЫ И МЕТОДЫ ИССЛЕДОВАНИЯ}

Для исследования нами были выбраны новые производные гетероциклических соединений с общим лабораторным шифром ЛХТ-, впервые синтезированные в $\mathrm{AO}$ «Всероссийский научный центр по безопасности биологически активных веществ» д.х.Н., профессором С.Я. Скачиловой. Вещества вводили внутрибрюшинно в виде взвеси с Твин-60 за 1 час до воздействия, в дозах, в которых они проявляли фармакологическую активность в ранее проведенных исследованиях [4, 6]. Животным контрольных групп в те же сроки и тем же путем вводили равный объем растворителя. Полученные результаты сравнивали с действием препаратов сравнения: родоначальником класса актопротекторов метапротом (этилтиобензимидазол, прежнее название - бемитил) и актопротектором с психо- и иммуностимулирующим действием ладастеном (адамантилбромфениламин, прежнее название - бромантан) [8].

Эксперименты были проведены на белых нелинейных мышах-самцах массой 20-24 г с соблюдением Правил лабораторной практики, принятых в Российской Федерации [5], и Международных рекомендаций Европейской конвенции по защите позвоночных животных, используемых при экспериментальных исследованиях [11].

Физическую работоспособность животных в условиях неблагоприятного температурного воздействия оценивали по плавательной пробе. Иммерсионную гипертермию моделировали при температуре воды $+40^{\circ} \mathrm{C}$; к корню хвоста животного прикрепляли груз, составляющий 5\% массы тела.
Иммерсионную гипотермию создавали при температуре воды $+6^{\circ} \mathrm{C}$; мыши плавали без утяжеления. Во всех случаях окончанием плавания считали момент опускания животного на дно бассейна с запрокидыванием головы; учитывали продолжительность плавания животных в минутах $[5,7]$.

Статистическую обработку проводили с использованием программного комплекса STATISTICA 6.0. Для выборок вычисляли среднее арифметическое $(\mathrm{M})$ и среднюю квадратическую ошибку (m), данные представляли в виде $\mathrm{M} \pm \mathrm{m}$. Достоверность различий оценивали по t-критерию Стьюдента (различия считали значимыми при $\mathrm{p}<0,05)$.

\section{РЕЗУЛЬТАТЫ ИССЛЕДОВАНИЯ И ИХ ОБСУЖДЕНИЕ}

Исследование физической работоспособности в условиях иммерсионной гипертермии показало, что среди новых соединений два вещества способны повышать продолжительность плавания животных в экстремальных условиях. Так, ЛХТ-4-97 в дозе 10 мг/кг значимо увеличивал продолжительность плавания мышей на $25 \%(\mathrm{p}<0,01)$, а ЛХТ-1-13 в дозе 1 мг/кг - на $23 \%(\mathrm{p}<0,05)$ (рис. 1). Соединения ЛХТ-21-01 (5 мг/кг) и ЛХТ-10-12 (10 мг/кг) существенно не влияли на данный показатель.

Препарат сравнения метапрот в дозах 50 и 100 мг/кг значимо не изменял продолжительность плавания мышей в условиях иммерсионной гипертермии, а ладастен в дозах 50 и 100 мг/кг значимо $(\mathrm{p}<0,05)$ увеличивал данный показатель на $16 \%$ и $20 \%$ соответственно. 


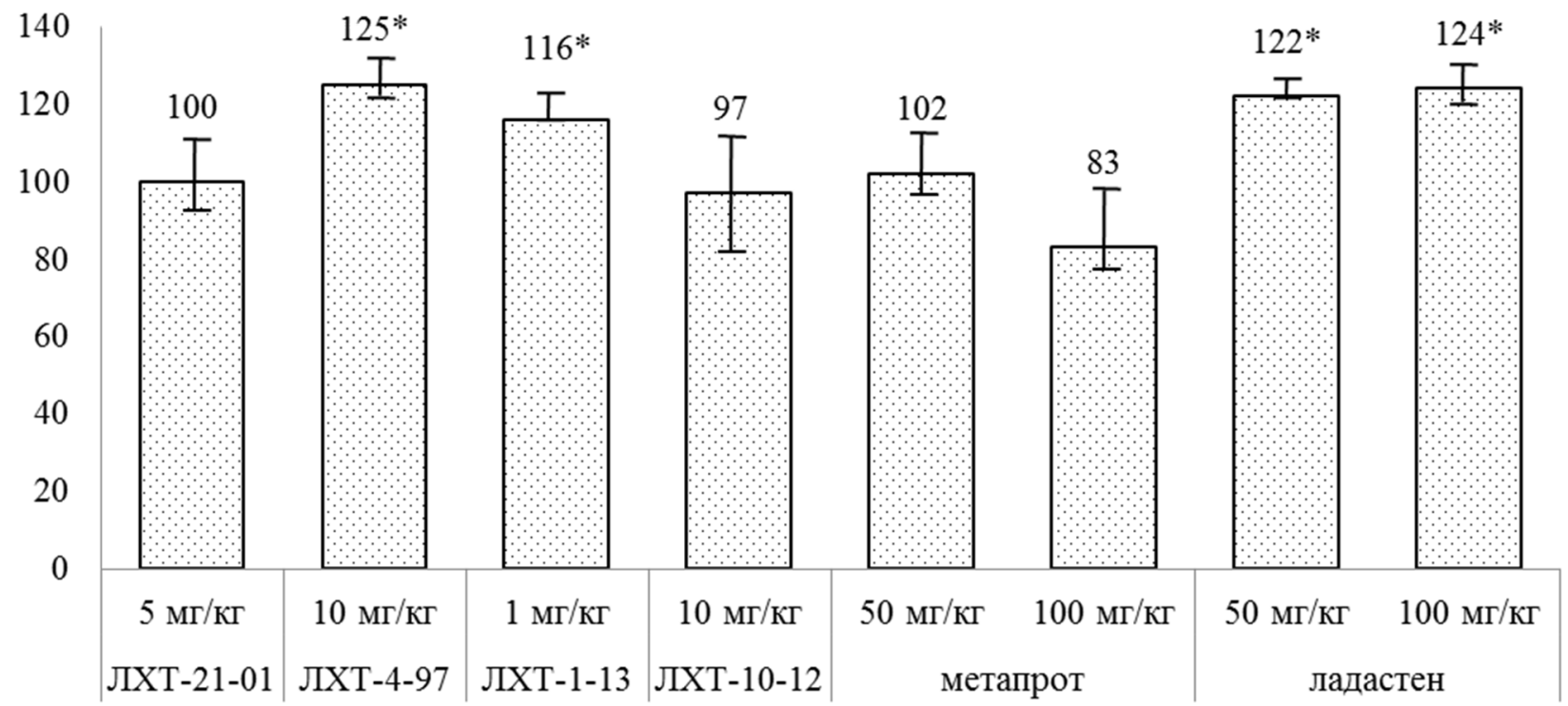

Рис. 2. Влияние исследованных соединений и препаратов сравнения на продолжительность плавания мышей в условиях иммерсионной гипотермии (в \% к контролю), $\mathrm{n}=8$.

При этом по выраженности актопротекторного действия ЛХТ-4-97 (10 мг/кг) и ЛХТ-1-13 (1 мг/кг) не уступали препарату сравнения ладастену (50 и 100 мг/кг).

В условиях иммерсионной гипотермии эффективными оказались также соединения ЛХТ4-97 и ЛХТ-1-13. Так, ЛХТ-4-97 в испытанной дозе значимо $(\mathrm{p}<0,05) \quad$ повышал продолжительность плавания животных на 25\%, а ЛХТ-1-13 - на 16\% (рис. 2). Другие исследованные вещества (ЛХТ-21-01 и ЛХТ-10-12) существенно не изменяли данный показатель.

Препарат сравнения метапрот в дозах 50 и 100 мг/кг значимо не изменял продолжительность плавания мышей в условиях иммерсионного охлаждения, а ладастен в дозах 50 и 100 мг/кг значимо $(\mathrm{p}<0,05)$ увеличивал данный показатель на $22 \%$ и $24 \%$ соответственно.

$$
\text { При этом по выраженности }
$$
актопротекторного действия ЛХТ-4-97 (10 мг/кг) и ЛХТ-1-13 (1 мг/кг) не уступали препарату сравнения ладастену (50 и 100 мг/кг).

Таким образом, можно заключить, что среди изученных новых производных гетероциклических соединений имеются вещества ЛХТ-4-97 и ЛХТ-1-13 - повышающие физическую работоспособность животных как в условиях гипер-, так и в условиях гипотермии. При этом указанные вещества являются эффективными в значительно меньших дозах, чем препарат сравнения ладастен.

\section{ЛИТЕРАТУРА}

1. Гельманова 3.С., Жаксыбаева Г.Ш., Гарт Н.А. Управление производственной средой для качественной работы на предприятии // Международный журнал прикладных и фундаментальных исследо- ваний. - 2015. - № 2-1. - Режим доступа: http://cyberleninka.ru/article/n/upravlenie-

proizvodstvennoy-sredoy-dlya-kachestvennoy-rabotyna-predpriyatii, свободный (06.05.2016).

2. Мбеди-МузитаМатондоЖильдас О., Невзорова Е.В., Гулин А.В. Оценка физиологических показателей функционального состояния металлургов в зависимости от возраста и стажа // Вестник Тамбовского университета. Серия: Естественные и технические науки. - 2013. - № 6 (2). - Режим доступа: $\quad$ http://cyberleninka.ru/article/n/otsenkafiziologicheskih-pokazateley-funktsionalnogosostoyaniya-metallurgov-v-zavisimosti-ot-vozrasta-istazha, свободный (06.05.2016).

3. Новиков В.С., Шустов Е.Б., Горанчук В.В. Коррекция функциональных состояний при экстремальных воздействиях. - СПб., 1998. - 544 с.

4. Петухова Н.Ф., Трошина М.В., Иванова Т.Г., Лютый Р.Ю., Цублова Е.Г., Яснечов В.В., Скачилова С.Я. Исследование антигипоксических свойств новых производных гетероциклических соединений и аминокислот в условиях острой кислородной недостаточности // Вестник Брянского государственного университета. - 2014. - № 4. C. 151-154.

5. Руководство по проведению доклинических исследований лекарственных средств. Часть первая. М. : Гриф и К, 2012. - 944 с.

6. Трочина М.В., Иванова Т.Г., Лютый Р.Ю., Цублова Е.Г., Яснецов В.В., Скачилова С.Я. Исследование влияния новых производных гетероциклических соединений и аминокислот на физическую работоспособность животных в обычных условиях // Научные ведомости БелГУ. Медицина. Фармация. - 2015. - № 4 (201). Вып. 29. - С. 176-179.

7. Фармакологическая коррекция физической работоспособности / под ред. Н.Н. Самойлова. - М. : Зеркало, 2002. - $120 \mathrm{c}$.

8. Федеральное руководство по использованию лекарственных средств (формулярная система). 
Выпуск XVI / А.Г. Чучалин, В.В. Яснецов (ред.). М. : Видокс, 2016. - 1045 с.

9. Шклярук В.Я. Адаптация человека к отрицательным воздействиям окружающей среды // Вестник ТГУ. - 2009. - № 7 . - Режим доступа: http://cyberleninka.ru/article/n/adaptatsiya-chelovekak-otritsatelnym-vozdeystviyam-okruzhayuscheysredy, свободный (06.05.2016).

10. Шустов Е.Б., Каркищенко Н.Н., Каркищенко В.Н. Обоснование направлений коррекции функционального состояния спортсменов исходя из мето- дологии экстремальных состояний // Биомедицина. - 2013. - № 3. - Режим доступа: http://cyberleninka.ru/article/n/obosnovanienapravleniy-korrektsii-funktsionalnogo-sostoyaniyasportsmenov-ishodya-iz-metodologii-ekstremalnyhsostoyaniy, свободный (06.05.2016).

11. European Convention for the Protection of Vertebrate Animals Used for Experimental and Other Scientific Purposes. - Strasbourg, 18.03.1986. - European Treaty Series. - № 123. 